\title{
BPI-fold (BPIF) containing/plunc protein expression in human fetal major and minor salivary glands
}

\section{Daniel Berretta Moreira ALVES ${ }^{(a)}$ Lynne BINGLE(b) \\ Colin David BINGLE(c) \\ Silvia Vanessa LOURENÇO(d) \\ Andréia Aparecida SILVA ${ }^{(a)}$ \\ Débora Lima PEREIRA(a) \\ Pablo Agustin VARGAS(a)}

\footnotetext{
(a) Universidade Estadual de Campinas - Unicamp, Piracicaba Dental School, Department of Oral Diagnosis, Piracicaba, SP, Brazil

(b) University of Sheffield, School of Clinical Dentistry, Academic Unit of Oral and Maxillofacial Pathology, Sheffield, UK;

(c) University of Sheffield, Medical School, Royal Hallamshire Hospital, Academic Unit of Respiratory Medicine, Sheffield, UK;

(d) Universidade de São Paulo - USP, School of Dentistry, Department of General Pathology, São Paulo-SP, Brazil.
}

Declaration of Interests: The authors certify that they have no commercial or associative interest that represents a conflict of interest in connection with the manuscript.

\section{Corresponding Author:}

Pablo Agustin Vargas

E-mail: pavargas@fop.unicamp.br

DOI: 10.1590/1807-3107BOR-2017.vol31.0006

Submitted: May 16, 2016

Accepted for publication: Oct 21, 2016

Last revision: Nov 23, 2016

\begin{abstract}
The aim of this study was to determine expression, not previously described, of PLUNC (palate, lung, and nasal epithelium clone) (BPI-fold containing) proteins in major and minor salivary glands from very early fetal tissue to the end of the second trimester and thus gain further insight into the function of these proteins. Early fetal heads, and major and minor salivary glands were collected retrospectively and glands were classified according to morphodifferentiation stage. Expression of BPI-fold containing proteins was localized through immunohistochemistry. BPIFA2, the major BPI-fold containing protein in adult salivary glands, was detected only in the laryngeal pharynx; the lack of staining in salivary glands suggested salivary expression is either very late in development or is only in adult tissues. Early expression of BPIFA1 was seen in the trachea and nasal cavity with salivary gland expression only seen in late morphodifferentiation stages. BPIFB1 was seen in early neural tissue and at later stages in submandibular and sublingual glands. BPIFA1 is significantly expressed in early fetal oral tissue but BPIFB1 has extremely limited expression and the major salivary BPIF protein (BPIFA2) is not produced in fetal development. Further studies, with more sensitive techniques, will confirm the expression pattern and enable a better understanding of embryonic BPIF protein function.
\end{abstract}

Keywords: Immunity, Innate; Immunohistochemistry; Humans; Salivary Glands.

\section{Introduction}

The BPI-fold (BPIF) containing/Plunc (palate, lung, and nasal epithelium clone) family of putative innate defence genes is located in a single locus on human chromosome 20q11.2, and members of the family are predominantly expressed in regions of the oral cavity, nasopharynx and upper respiratory tract. ${ }^{1}$ Protein expression of the prototy pic family member, BPIFA1/Plunc, (palate, lung and nasal epithelium clone) was first described in the nasal epithelium of the mouse embryo and the trachea/bronchi of adult mice. ${ }^{2}$ An extended family of proteins was subsequently identified, and these are now known to make up the largest branch of a lipid transfer protein family that includes phospholipid transfer protein (PLTP), cholesterol ester transfer protein (CETP), bactericidal permeability increasing protein (BPI) and LPS-binding protein (LBP). ${ }^{3,4,5}$ The considerable structural similarity 
across the PLUNC/BPI family suggested that PLUNC proteins might function by binding lipid molecules and this led to the hypothesis that PLUNCs may share host defence functions with BPI and LBP. ${ }^{6,7,8}$

BPIF proteins exist as two subgroups; BPIFA proteins (formally SPLUNCs) and BPIFB proteins (formally LPLUNCs). BPIFA proteins have structural homology to the N-terminal domain of BPI whereas BPIFB proteins have structural homology to both domains of BPI. ${ }^{4,7}$

BPIF proteins appear to exhibit distinct tissue and cell specific expression patterns with various family members being localised to a number of different glandular structures within the upper respiratory tract, nasopharyngeal regions and oral cavity. ${ }^{1}$ The proteins are secreted from these tissues and are found in high levels in saliva and nasal and respiratory lining fluids. Expression studies on the human proteins have largely focused on a few members of the family, including BPIFA1, BPIFA2, and BPIFB1, and have largely been carried out on adult tissues. ${ }^{901,11,12}$ Expression and localization of the proteins in developing tissues has been given little attention since the first description of BPIFA1 (PLUNC) by Weston et al. ${ }^{2}$ To date only one study, by Zhou et al., ${ }^{13}$ has investigated BPIF protein expression in human fetal tissue. They carried out an immunohistochemical study on 37 different tissues from on 28-30 week human fetuses and found positive BPIFA1 expression in all of the major salivary glands. They described positive expression in both serous and mucus cells, which is in contrast to previous studies carried out with adult tissues where expression appears to be limited to mucus cells. ${ }^{10,11}$

The aim of this study was to assess the immunohistochemical expression pattern of three BPIF proteins in head and neck tissues from very early human fetuses and in the major and minor salivary glands, tongue and palate of later-stage human fetuses.

\section{Methodology}

\section{Sample Characteristics}

The Human Developmental Biology Resource (Newcastle, UK) provided fetal head sections (eight, nine, and 12 weeks). Archived formalin-fixed, paraffin-embedded tissue blocks of salivary glands, palate, and tongue of 26 human fetuses (12 to 25 intrauterine weeks) were obtained from the Department of General Pathology, School of Dentistry, University of São Paulo, Brazil. Twenty-five major salivary glands were collected, comprising seven parotid, 13 submandibular and five sublingual glands and 33 minor salivary glands from the lip $(n=18)$, tongue $(n=6)$, and palate $(n=9)$. Ethical approval for this study was granted by the Newcastle and North Tyneside Local Research Ethics Committee and by the Research Ethics Committee of the Faculty of Dentistry, Piracicaba, State University of Campinas (FOP-UNICAMP Protocol Number 114/2009), Brazil.

\section{Immunohistochemical analysis}

Thestudy wascarried out using immunohistochemical techniques described previously in detail. ${ }^{10,14}$ BPIFA2 antibodies were custom made, affinity-purified, anti-peptide antibodies from Eurogentec with full characterization, as described in Bingle et al. ${ }^{12}$ Briefly, all tissues were formalin-fixed and paraffin embedded and $4 \mu \mathrm{M}$ sections were treated with $3 \%$ hydrogen peroxide in methanol to quench endogenous peroxidase. Sections to be incubated with BPIFA2A were subjected to antigen retrieval; they were immersed in $0.01 \mathrm{M}$ sodium citrate and microwaved for 8 min. ${ }^{12}$ Sections were incubated with $100 \%$ normal goat serum at room temperature for $30 \mathrm{~min}$ and then at $4^{\circ} \mathrm{C}$ overnight with affinity purified polyclonal primary antibodies diluted in $100 \%$ goat serum (Sigma-Aldrich, Gillingham, Dorset, UK; BPIFA2A [1:250], BPIFA2B [1:500] and BPIFB1 [1:600]). We also used a polyclonal BPIFA1 antibody (1:300 dilution), as described by Campos et al. ${ }^{15}$ Rabbit IgG (DAKO, Ely, Cambridgeshire, UK) was used as a negative control. A Vectastain Elite $A B C$ kit (Vector Laboratories, Peterborough, Northants, UK) containing an appropriate biotin-labeled secondary antibody was used, according to the manufacturer's instructions. Peroxidase enzymatic development was performed using a Vector NovaRed substrate kit (Vector Laboratories, Peterborough, Northants, UK) resulting in red staining in positive cells. Sections were counterstained with hematoxylin, dehydrated to xylene, and mounted in DPX. 
The respiratory epithelium of the palate region and the tongue surface epithelium were also assessed for expression of BPIFA1, BPIFA2 and BPIFB1.

\section{Morphodifferentiation stages}

To evaluate immunohistochemical expression patterns, the major and minor salivary glands were classified according to the five morphodifferentiation stages (prebud, initial bud, pseudoglandular, canalicular, and terminal bud stages) described by Tucker. ${ }^{16}$

\section{Evaluation of immunohistochemical staining}

Immunohistochemical staining with all antibodies in all tissues was classified as either positive or negative.

\section{Results}

Whole fetal heads from eight to 12 week fetuses were analyzed alongside major and minor salivary glands from 26 fetuses, which were assessed according to the location of the gland and the predominant morphodifferentiation stage (Table 1).

In the early stages of development (eight and nine week fetuses), BPIFA1 specific staining was limited to the epithelial cells lining the nasal cavity, nasal capsule and laryngeal pharynx (Figure 1), and also the surface cells of the tongue and rudimentary submandibular gland cells (Figure 2). Expression of BPIFA2 and BPIFB1 was extremely limited with BPIFA2 only being detected in the laryngeal pharynx (Figure 3) and BPIFB1 being seen in small areas of the developing brain.

Tissues collected from later stages of development (intrauterine age 12 to 25 weeks) also showed limited expression of these proteins as only BPIFA1 and BPIFB1 were detected; no BPIFA2 positive staining was ever seen in later stage tissues. BPIFA1 was detected in only 13 of the 26 fetuses studied but this did include all major and minor glands examined apart from the parotid gland. BPIFB1 exhibited a more limited expression profile as the protein was only detected in two of the 26 fetuses, one submandibular gland, and one sublingual gland (Table 2).

Of the total 58 salivary glands analyzed, $17(29 \%)$ were positive for BPIFA1. Sixteen of the 58 glands were from the pseudoglandular stage but none of these expressed BPIFA1, 22 were at the canalicular stage, four $(18 \%)$ of which expressed BPIFA1, and 20 were from the terminal bud stage with 13 (65\%) expressing BPIFA1. Twenty-five major salivary glands were assessed. Eight were positive for BPIFA1, including four submandibular glands at the canalicular stage. Four of the five sublingual glands evaluated $(80 \%)$ were positive for BPIFA1 and these predominantly had a terminal bud morphodifferentiation pattern. No parotid glands expressed BPIFA1 but this is in keeping with the expression pattern seen post-natally. Thirty-three minor salivary glands were examined and of these nine $(27 \%)$ were positive for BPIFA1, all from the terminal bud morphodifferentiation stage. Four of the 18 lip glands (22\%), two of the six tongue glands (33\%) and three of the nine palate glands (33\%) assessed were positive for BPIFA1. In glands in the canalicular stage, BPIFA1 was found in mucin plugs and within the primitive striated ducts (Figure 4), whereas in the glands in the terminal bud stage it was expressed in mucous cells of the primitive mucous tubules and in the cytoplasm of epithelial and myoepithelial cells of primitive acini (Figure 5).

Table 1. Representation of the assessed samples according to the type of salivary gland and the predominant morphodifferentiation stage. N (\%).

\begin{tabular}{lcccc}
\hline Location & Pseudoglandular & Canalicular & Terminal bud & Total \\
\hline Parotid & $2(29 \%)$ & $5(71 \%)$ & 0 & $7(100 \%)$ \\
Submandibular & 0 & $12(92 \%)$ & $1(8 \%)$ & $13(100 \%)$ \\
Sublingual & $1(20 \%)$ & 0 & $4(80 \%)$ & $5(100 \%)$ \\
Palate & $4(44 \%)$ & $1(11 \%)$ & $4(44 \%)$ & $9(100 \%)$ \\
Lip & $5(28 \%)$ & $4(22 \%)$ & $9(50 \%)$ & $18(100 \%)$ \\
Tongue & $4(67 \%)$ & 0 & $2(33 \%)$ & $6(100 \%)$ \\
Total & 16 & 22 & 20 & 58 \\
\hline
\end{tabular}

$\mathrm{N}=$ number; $(\%)=$ percentage. 


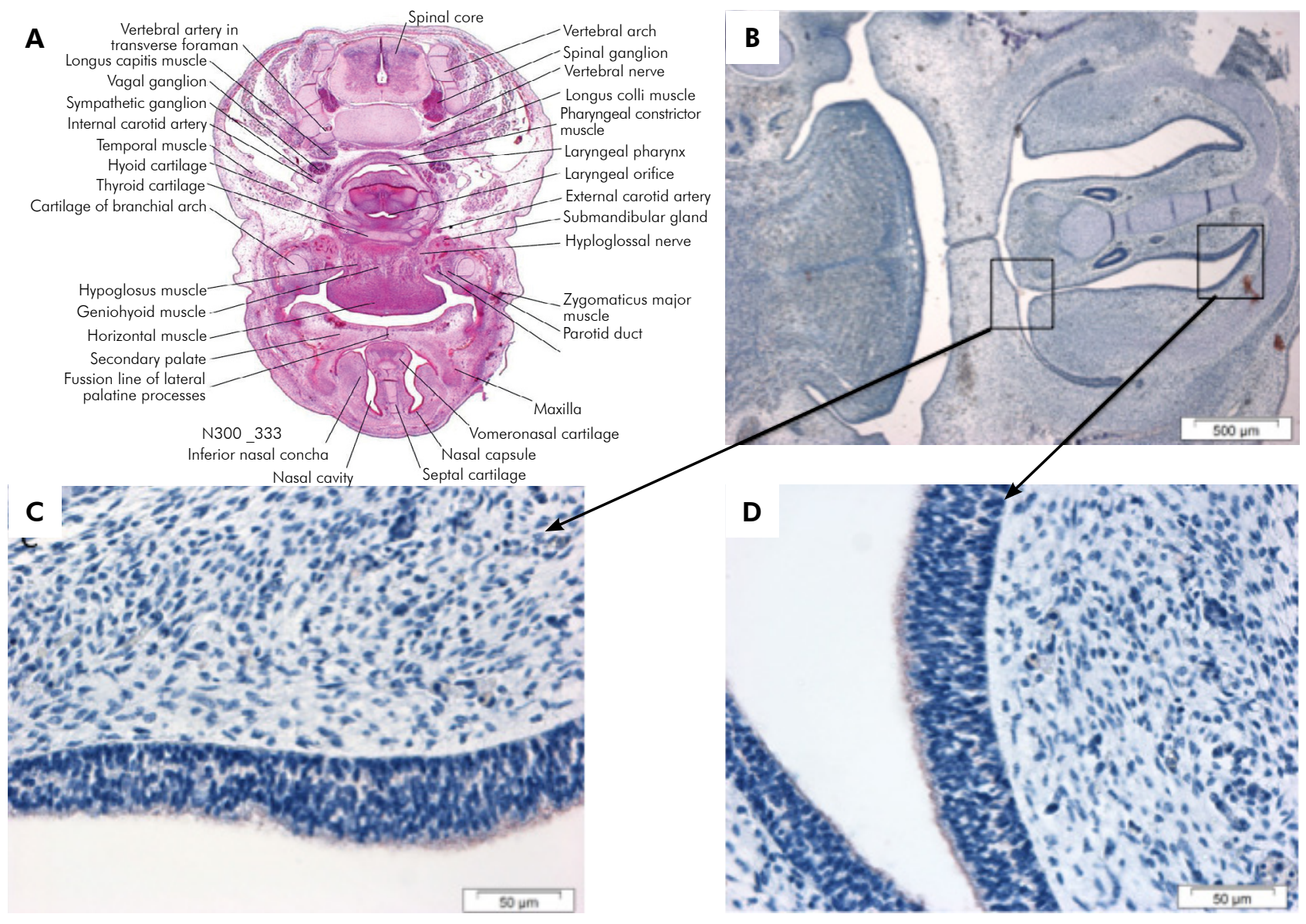

Figure 1. BPIFA1 expression in 8-week fetal head. A: Overview of structures in head section; B: Low power image depicting nasal cavity; C and D: Higher power images depicting positive BPIFAl staining in nasal cavity. Magnification shown on image.

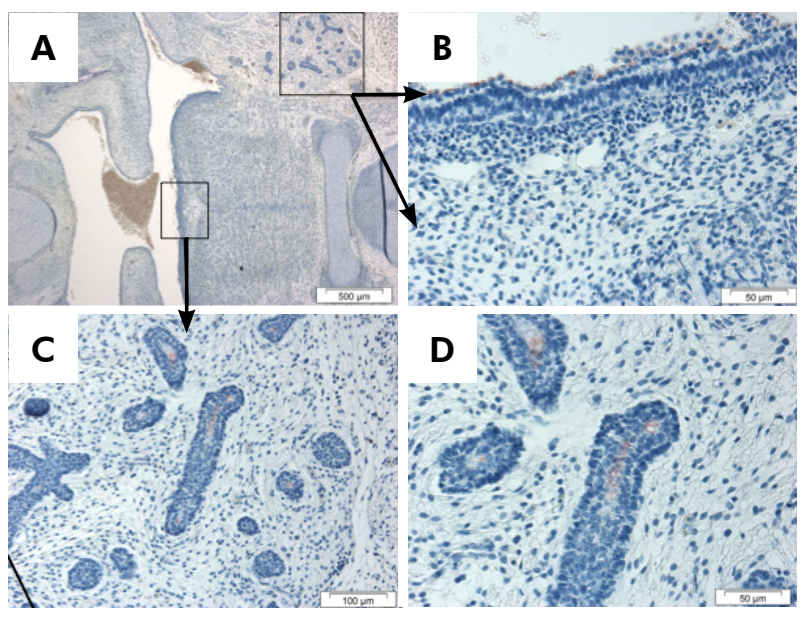

Figure 2. BPIFAl expression in tongue and glands of 9 week fetal head. A: Low power image of rudimentary salivary glands and tongue epithelium; B: Higher power illustrating BPIFA1 expression in early tongue epithelium; C and D: Higher power images depicting BPIFA1 in rudimentary submandibular gland. Magnification shown on image.
BPIFB1 expression was much less frequently observed with only two of the 26 fetuses showing any positivity and then only in one submandibular and one sublingual gland. The distinct areas which appeared to be expressing BPIFB1, were the luminal poles of ductal cells (Figure 6).

During our evaluation of the major and minor salivary glands it was noted that some adjacent tissue types also stained positively for BPIFA1. For example, three of the six tongue sections demonstrated expression of BPIFA1 in the squamous epithelium (Figure 7) and six of the nine minor glands from the palate had respiratory epithelium associated; ciliated cells from this region were strongly positive for BPIFA1 (Figure 7). BPIFA2 and BPIFB1 were not expressed in the respiratory epithelium. 

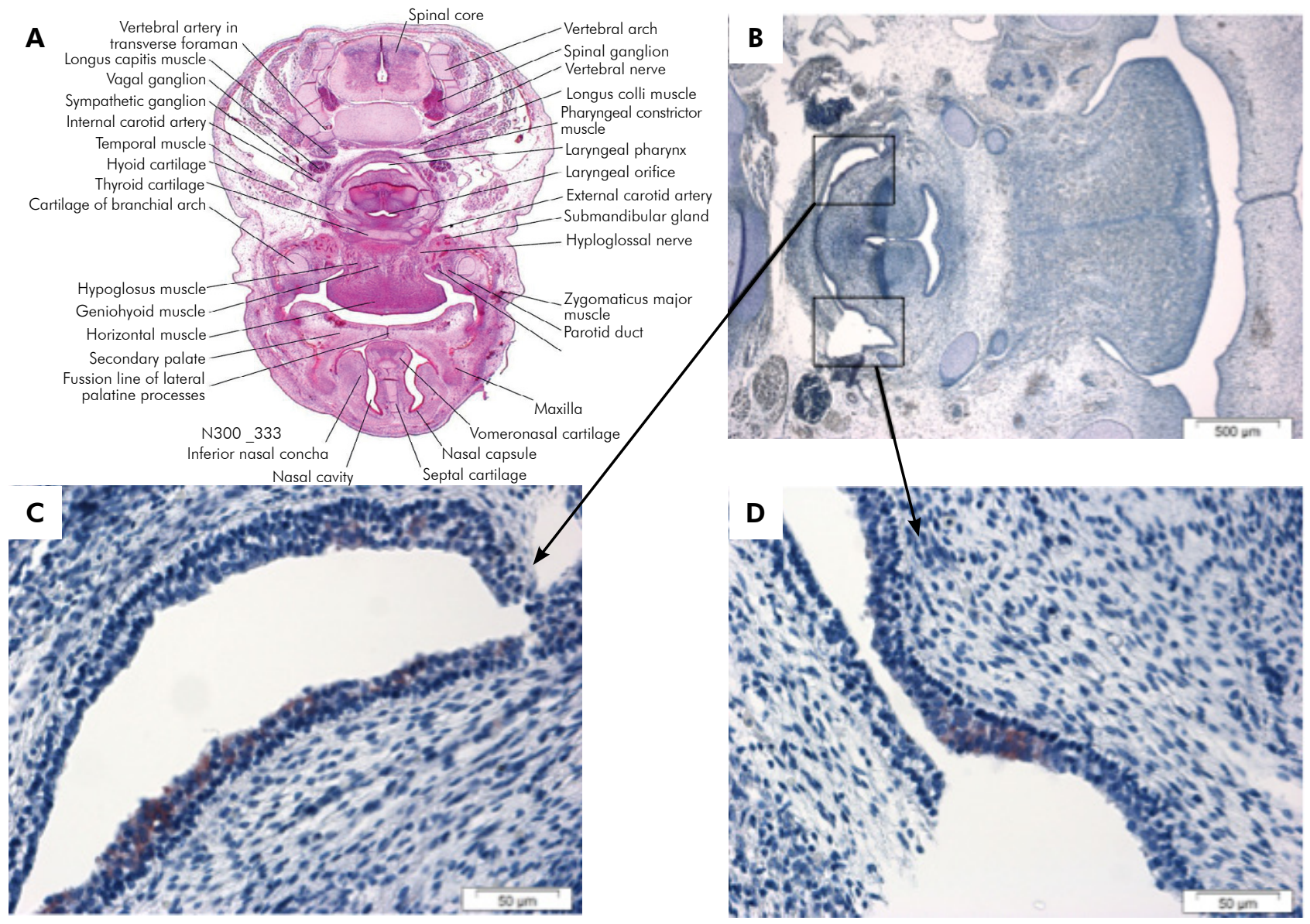

Figure 3. BPIFA2 expression in laryngeal pharynx of 8 week fetal head. A: Overview of structures in head section; B: Low power image of laryngeal pharynx; $C$ and D: Higher power images showing positive expression of BPIFA2 in laryngeal pharynx. Magnification shown on image.

Table 2. Representation of all samples of major and minor salivary glands according to the expression of BPIFA 1 , BPIFA2A, BPIFA2B and BPIFB1. N.

\begin{tabular}{lccc}
\hline Location & BPIFA1 & BPIFA2 & BPIFB1 \\
\hline Parotid & 0 & 0 & 0 \\
Submandibular & 4 & 0 & 1 \\
Sublingual & 4 & 0 & 1 \\
Palate & 3 & 0 & 0 \\
Lip & 4 & 0 & 0 \\
Tongue & 2 & 0 & 0 \\
Total & 17 & 0 & 2 \\
\hline
\end{tabular}

$\mathrm{N}=$ positive samples.

\section{Discussion}

The function of the BPIF protein family has not yet been fully elucidated, although there is increasing evidence that it may play a role in innate immunity. ${ }^{7,7,18,19,20}$ The expression of a number of family members in adult human tissues is well documented but to date there is only one study describing expression in human fetal salivary gland tissue and that was limited to relatively late stage of development (28-30 weeks). ${ }^{13}$ In the present study we have used whole head sections from 8-12 week fetuses and major and minor salivary glands from 12 to 25 weeks.

None of the major or minor salivary glands evaluated in this study were positive for BPIFA2, the major BPIF protein secreted into adult saliva from all major and minor glands. Our previous studies have suggested that BPIFA2 is not only secreted from the serous cells ${ }^{20}$ but is also produced within the intralobular and interlobular ducts of the salivary glands and serous demilunes of the minor salivary glands. ${ }^{12}$ This is the first study to attempt to determine 
the expression of this protein in fetal tissue and our results suggest that production and secretion of BPIFA2 is closely associated with the enzymatic activity of secretory granules of serous cells, which only occurs in the first week of life. In addition, rodent parotid secretory protein (PSP, homologous with human BPIFA2) is also only expressed post-natally. ${ }^{21,22,23}$

We also previously described the expression of BPIFB1 in the duct cells of adult major salivary glands, ${ }^{14}$ but to date there are no studies that show expression in the salivary glands of human fetuses. In our study, BPIFB1 was only detected in neural tissue of the very early fetuses and in the luminal pole of duct cells in two of the major salivary glands examined; these were in the canalicular and terminal bud morphodifferentiation stages. As this protein was found in such a small number of the tissues examined, we suggest that further investigation using more sensitive laboratory techniques, such as in situ hybridization, is needed.

BPIFA1 protein was detected in the nasal cavity, nasal capsule, and laryngeal pharynx of the very early fetuses and in both major and minor salivary glands of 13 of the 26 later-stage human fetuses studied. Zhou et al. ${ }^{13}$ detected expression of BPIFA1 in

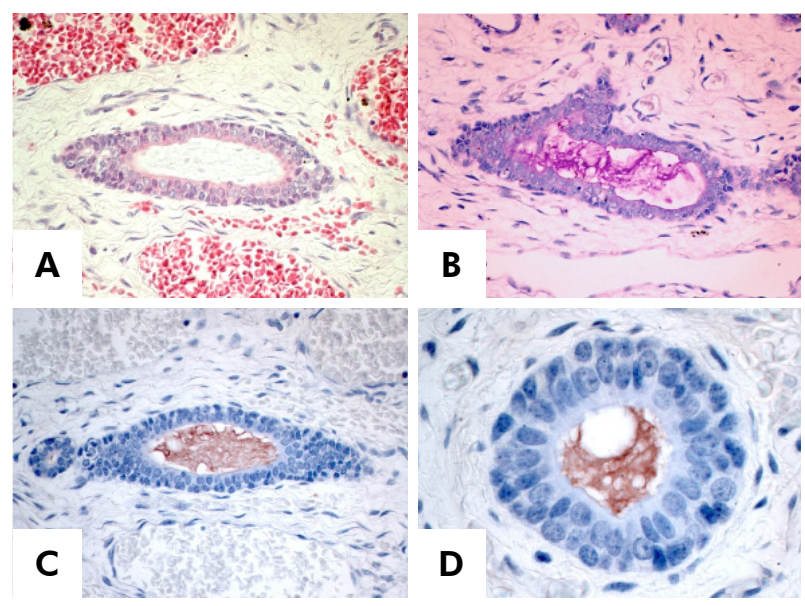

Figure 4. BPIFAI localization in canalicular and terminal bud stage salivary glands. A: Hematoxylin \& Eosin (H\&E), Submandibular gland, Canalicular stage, 21 weeks (original magnification 400X); B: Periodic Acid Schiff (PAS), mucin plug PAS positive (original magnification 400X); C: BPIFA1 expression in mucin plug of striated duct (original magnification 400X); D: BPIFA 1 in mucin plug of striated duct (original magnification 1000X).

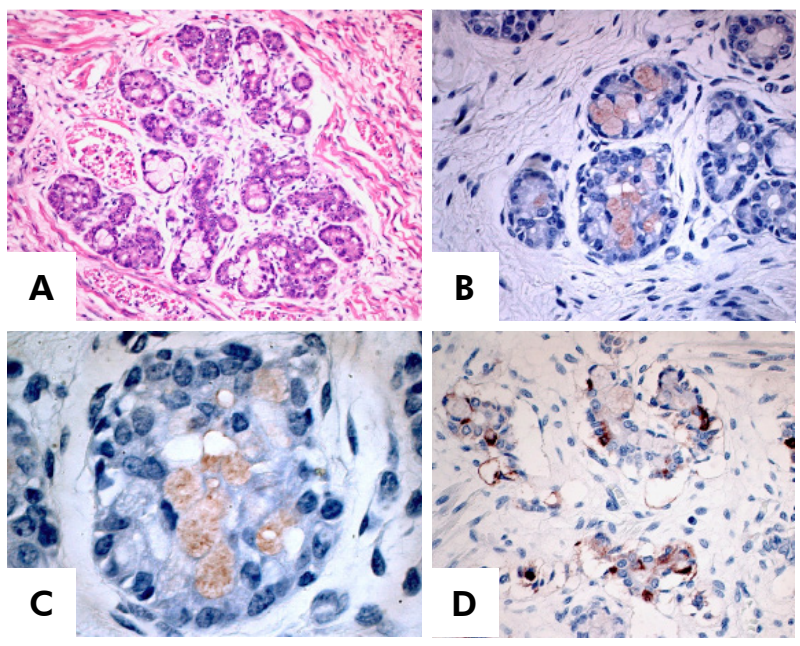

Figure 5. BPIFAl is also produced by fetal minor salivary glands. A: H\&E, Minor salivary gland of lip, Terminal bud stage, 22 weeks; B: BPIFA1 in mucous cells of the primitive mucous tubules; C: High power view of B; D: BPIFA1 in myoepithelial and ductal cells of primitive acini.
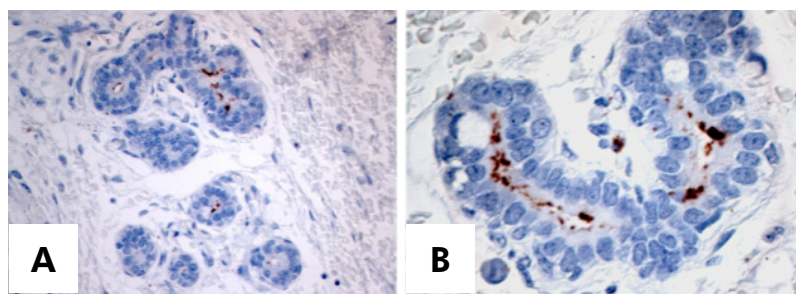

Figure 6. BPIFB 1 is only expressed in a minority of fetal submandibular and sublingual glands. A: Submandibular gland, Canalicular stage, 21 weeks, BPIFB 1 expression in luminal pole of ductal cells (original magnification 400X); B: High power view of $A$ (original magnification 1000X).

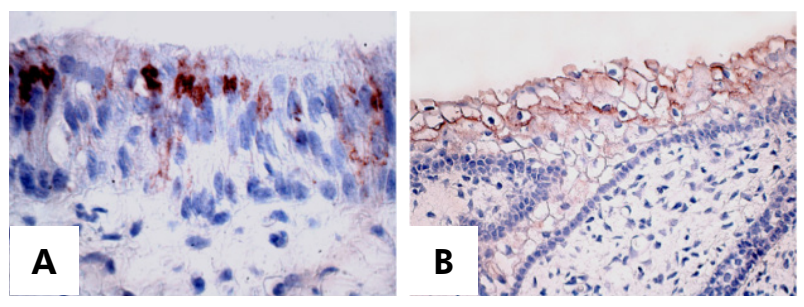

Figure 7. Respiratory tissue associated with the tongue indicated epithelial cells early in development produce BPIFA 1 . A: Respiratory epithelium, 16 weeks, BPIFA1 expression in ciliated cells of the respiratory epithelium (original magnification 1000X); B: Tongue epithelium, 17 weeks, BPIFA1 expression in the squamous epithelium of the tongue surface (original magnification 1000X). 
both mucous and serous cells of fetal submandibular glands but in our study submandibular expression of BPIFA1 occurred mainly in the mucin plugs of striated ducts. In adult glands the protein is only expressed in mucous cells of both major and minor glands. ${ }^{12}$

Zhou et al. ${ }^{13}$ also found strong expression of BPIFA1 in the parotid glands of their fetuses, however, none of the seven parotids evaluated in our study were positive for BPIFA1 or any other marker used, and BPIFA1 has never been detected in adult parotid glands. BPIFA2 is highly expressed in adult parotid glands and so it was somewhat surprising to note that the protein is not expressed in fetal glands. However, despite being the first salivary gland to form, development is slow with the first production of salivary proteins occurring between the 25th and 32nd weeks of intra-uterine life, and the first secretory granules forming after birth. ${ }^{21,22,23,24}$ This is all considerably later in development than the tissues we were able to obtain for evaluation.

The expression of BPIFA1 in fetal sublingual glands and minor salivary glands has not previously been assessed. Bingle et al. ${ }^{12}$ detected the cytoplasmic expression of BPIFA1 protein in mucous acini and mucin plugs in the ducts of the sublingual glands and minor salivary glands of adults. In the present study, BPIFA1 localized mainly in the cytoplasm of mucous cells in the primitive tubules of sublingual glands, although in one case the cytoplasm of myoepithelial and ductal cells of primitive acini was also positive. BPIFA1 similarly localized in the cytoplasm of mucous cells in tubules from minor salivary glands of the lip, the palate, and the tongue and one gland associated with the tongue demonstrated BPIFA1 protein production in the cytoplasm of ductal cells of primitive acini. This is therefore the first study to describe intrauterine expression of BPIFA1 in sublingual glands and minor salivary glands of the lip, palate and tongue region. Further studies are needed however, to elucidate the role of this protein in the embryonic period.

The expression of the BPIFA1 protein in the epithelium of the upper airways of human adults is well described, ${ }^{10}$ however the function has also not yet been fully elucidated. Thus, various studies have investigated the relationship of these proteins in the host defense system against aggressive agents. ${ }^{25,26,27,28,29}$ Ciliated cells found in respiratory epithelium adjacent to palatal minor salivary glands demonstrated positive expression of BPIFA1. We also found early expression (from eight weeks) in epithelial cells lining the nasal cavity, nasal capsule, and laryngeal pharynx and in surface cells of the tongue. LeClair et al. ${ }^{30}$ investigated the expression of BPIFA1 in murine embryonic epithelium of the nasopharynx and Zhou et al. ${ }^{13}$ observed expression in the squamous and columnar epithelium of the nose, palate, pharynx and tracheal region of late-stage human fetuses, but neither study described expression of BPIFA1 in the nasal septa. Further studies are needed to evaluate the expression of BPIFA1 in fetal respiratory epithelium as this has not previously been described and will further validate our initial findings. Such a study would also help to elucidate the role of BPIFA1 during this stage of human development.

Whole head sections from the early stages of fetal development and lingual minor salivary glands indicated that BPIFA1 is also secreted from the squamous epithelium of the tongue surface. Interestingly we have found similar expression in adult tissue and LeClair et al. (2004) showed that a member of the BPIF family exclusive to mice, BPIFA5, was only expressed in the intrapapillar epithelium of the dorsal surface of the tongue. ${ }^{10,31}$ We believe this is the first time such expression has been demonstrated in human fetal tissue.

The onset of BPIFA1 protein expression in human fetal salivary glands seems to be related to the morphodifferentiation stage of the gland as the BPIFA1-positive samples were predominantly associated with the more advanced morphodifferentiation stages (canalicular and terminal bud). According to Tucker ${ }^{16}$, the salivary glands, despite being well differentiated in these stages, will only reach full maturity in the postnatal period. Our results suggest that in the submandibular glands, BPIFA1 is produced during the canalicular stage of morphodifferentiation. However, not all submandibular glands demonstrated positive staining and it is difficult to explain why a significant number of submandibular glands at this stage $(n=8)$ and the sample collected from the terminal bud stage, did not appear to be producing the protein. The sublingual 
glands and minor salivary glands of the lip, palate and tongue region seem to initiate the production of BPIFA1 during the terminal bud stage, however, again this was not the case in all samples. The material used in this study, for the later stages of development, came from an archive that consisted of paraffin-embedded tissue blocks. Thus, the tissues may have suffered autolysis at the time of collection or there may have been problems associated with the fixation process which could have interfered with the antigen/antibody interaction. It is also possible that there is some genetic variability that has yet to be investigated.

This is the first description of the expression of three members of the BPIF protein family (BPIFA1, BPIFA2, BPIFB1) in major and minor salivary glands, in the palate and in tongue epithelium in human fetuses. BPIFA1 expression in the major and minor salivary glands begins during the intrauterine period but at advanced stages of morphodifferentiation. The ciliated cells of the respiratory epithelium also produce BPIFA1 in the intrauterine period and, for the first time, the expression of BPIFA1 in the squamous epithelium of the fetal tongue has been

\section{References}

1. Bingle L, Bingle CD. Distribution of human PLUNC/ BPI fold-containing (BPIF) proteins. Biochem Soc Trans. 2011;39(4):1023-7. doi:10.1042/BST0391023

2. Weston WM, LeClair EE, Trzyna W, McHugh KM, Nugent $\mathrm{P}$, Lafferty $\mathrm{CM}$ et al. Differential display identification of plunc, a novel gene expressed in embryonic palate, nasal epithelium and adult lung. J Biol Chem. 1999;274(19):13698-703. doi:10.1074/jbc.274.19.13698

3. Bingle CD, LeClair EE, Havard S, Bingle L, Gillingham, Craven CJ. Phylogenetic and evolutionary analysis of the PLUNC gene family. Protein Sci. 2004;13(2):422-30. doi:10.1110/ps.03332704

4. Bingle CD, Bingle L, Craven CJ. Distant cousins: genomic and sequence diversity within the BPI fold-containing (BPIF)/PLUNC protein family. Biochem Soc Trans. 2011;39(4):961-5. doi:10.1042/BST0390961

5. Bingle CD, Seal RL, Craven CJ. Systematic nomenclature for the PLUNC/PSP/BSP30/SMGB proteins as a subfamily of the BPI fold-containing superfamily. Biochem Soc Trans. 2011;39(4):977-83. doi:10.1042/BST0390977

6. Beamer, Carroll SF, Eisenberg D. Crystal structure of human BPI and two bound phospholipids at recorded. BPIFA2 had extremely limited expression in the very early tissues, as the only region to stain positively for the presence of this protein was the laryngeal pharynx; no expression was found in fetal salivary glands. BPIFB1 was detected in only two cases studied, and thus requires further investigation.

\section{Conclusion}

BPIFA1 is significantly expressed in early fetal oral tissue but BPIFB1 has extremely limited expression and the major salivary BPIF protein (BPIFA2) is not produced in fetal development. Further studies, with more sensitive methods, would allow quantification of BPFI protein expression which may lead to a better understanding of their role in embryonic development and potentially clarification of their post-natal role.

\section{Aknowledgment}

The authors would like to thank The National Council for Scientific and Technological Development (Cnpq 305967/2014-2 and Cnpq PVE 400039/2014-1) for their support.
2.4 angstrom resolution. Science. 1997;276(5320):1861-4. doi:10.1126/science.276.5320.1861

7. Bingle CD, Craven J. PLUNC: a novel family of candidate host defense proteins expressed in the upper airways and nasopharynx. Hum Mol Genet. 2002;11(8):932-43. doi:10.1093/hmg/11.8.937

8. Bingle CD, Craven CJ. Comparative analysis of the PLUNC (palate, lung and nasal epithelium clone) protein families. Biochem Soc Trans. 2003;31(4):806-9. doi:10.1042/bst0310806

9. Geetha C, Venkatesh SG, Dunn BH, Gorr SU. Expression and anti-bacterial activity of human parotid secretory protein (PSP). Biochem Soc Trans. 2003;31(4):815-8. doi:10.1042/bst0310815

10. Bingle L, Cross SS, High AS, Wallace WA, Devine DA, Havard S, et al. SPLUNC1 (PLUNC) is expressed in glandular tissues of the respiratory tract and in lung tumours with a glandular phenotype. J Pathol. 2005;205(4):491-7. doi:10.1002/path.1726

11. Bingle L, Barnes FA, Cross SS, Rassl D, Wallace WA, Campos MA et al. Differential epithelial expression of the putative innate immune molecule SPLUNC1 in cystic fibrosis. Respir Res. 2007;8(1):79. doi:10.1186/1465-9921-8-79 
12. Bingle L, Barnes FA, Lunn H, Musa M, Webster S, Douglas CW et al. Characterisation and expression of SPLUNC2, the human orthologue of rodent parotid secretory protein. Histochem Cell Biol. 2009;132(3):339-49. doi:10.1007/s00418-009-0610-4

13. Zhou HD, Fan SQ, Zhao J, Huang DH, Zhou M, Liu HY et al. Tissue distribution of the secretory protein, SPLUNC1, in the human fetus. Histochem Cell Biol. 2006;125(3):315-24. doi:10.1007/s00418-005-0070-4

14. Vargas PA, Speight PM, Bingle CD, Barrett AW, Bingle L. Expression of PLUNC family members in benign and malignant salivary gland tumours. Oral Dis. 2008;14(7):613-9. doi:10.1111/j.1601-0825.2007.01429.x

15. Campos MA, Abreu AR, Nlend MC, Cobas MA, Conner GE, Whitney PL. Purification and characterization of PLUNC from human tracheobronchial secretions. Am J Respir Cell Mol Biol. 2004;30(2):184-92. doi:10.1165/rcmb.2003-0142OC

16. Tucker AS. Salivary gland development. Semin Cell Dev Biol. 2007;18(2):237-44. doi:10.1016/j.semcdb.2007.01.006

17. Chu HW, Thaikoottathil J, Rino JG, Zhang G, Wu Q, Moss T, et al. Function and regulation of SPLUNC1 protein in Mycoplasma infection and allergic inflammation. J Immunol. 2007;179(6):3995-4002. doi:10.4049/jimmunol.179.6.3995

18. Bartlett JA, Hicks BJ, Schlomann JM, Ramachandran S, Nauseef WM, McCray PB Jr. PLUNC is a secreted product of neutrophil granules. J Leukoc Biol. 2008;83(5):1201-6. doi:10.1189/jlb.0507302

19. Abdolhosseini M, Sotsky JB, Shelar AP, Joyce PB, Gorr SU. Human parotid secretory protein is a lipopolysaccharide-binding protein: identification of an anti-inflammatory peptide domain. Mol Cell Biochem. 2012;359(1-2):1-8. doi:10.1007/s11010-011-0991-2

20. Liu Y, Di ME, Chu HW, Liu X, Wang L, Wenzel S et al. Increased susceptibility to pulmonary Pseudomonas infection in Splunc1 knockout mice. J Immunol. 2013;191(8):4259-68. doi:10.4049/jimmunol.1202340

21. Redman RS, Field RB. Chronology of peroxidase activity in the developing rat parotid gland. Anat Rec. 1993;235(4):611-21. doi:10.1002/ar.1092350414
22. Denny PC, Ball WD, Redman RS. Salivary glands: a paradigm for diversity of gland development. Crit Rev Oral Biol Med. 1997;8(1):51-75. doi:10.1177/10454411970080010301

23. Ball WD, Mirels L, Hand AR. Psp and Smgb: a model for developmental and functional regulation in the rat major salivary glands. Biochem Soc Trans. 2003;31(4):777-80. doi:10.1042/bst0310777

24. Redman RS, Sreebny LM. Morphologic and biochemical observations on the development of the rat parotid gland. Dev Biol. 1971;25(2):248-79. doi:10.1016/0012-1606(71)90030-3

25. Bingle L, Wilson K, Musa M, Araujo B, Rassl D, Wallace WA et al. BPIFB1 (LPLUNC1) is upregulated in cystic fibrosis lung disease. Histochem Cell Biol. 2012;138(5):749-58. doi:10.1007/s00418-012-0990-8

26. Musa M, Wilson K, Sun L, Mulay A, Bingle L, Marriott HM et al. Differential localisation of BPIFA1 (SPLUNC1) and BPIFB1 (LPLUNC1) in the nasal and oral cavities of mice. Cell Tissue Res. 2012;350(3):455-64. doi:10.1007/s00441-012-1490-9

27. Wu MM, Sun H, Nan Q. Expression and clinical significance of PLUNC protein in nasal polyp and chronic sinusitis tissue. Ear Nose Throat J. 2012;91(7):282-5.

28. Hamilos DL. Host-microbial interactions in patients with chronic rhinosinusitis. J Allergy Clin Immunol. 2013;131(4):1263-4. doi:10.1016/j.jaci.2013.02.020

29. Tsou YA, Peng MT, Wu YF, Lai CH, Lin CD, Tai CJ et al. Decreased PLUNC expression in nasal polyps is associated with multibacterial colonization in chronic rhinosinusitis patients. Eur Arch Otorhinolaryngol. 2014; 271(2):299-304. doi:10.1007/s00405-013-2535-8

30. LeClair EE, Nguyen L, Bingle L, MacGowan A, Singleton V, Ward SJ, et al. Genomic organization of the mouse plunc gene and expression in the developing airways and thymus. Biochem Biophys Res Commun. 2001;284(3):792-7. doi:10.1006/bbrc.2001.5024

31. LeClair EE, Nomellini V, Bahena M, Singleton V, Bingle L, Craven CJ, et al. Cloning and expression of a mouse member of the PLUNC protein family exclusively expressed in tongue epithelium. Genomics. 2004;83(4):658-66. doi:10.1016/j.ygeno.2003.09.015 